Conclusions According to our study, FSE constitutes a reliable method in detecting unsuspected invasive cervical cancer. Despite the increased surgical duration and the potential to augment intraoperative complications, FSE can be used in the interest of optimal management by preventing bimodal treatment and long-term morbidity.

\section{EPV083/\#547 LOCALLY ADVANCED CERVICAL CARCINOMA (LACC) SUBMITTED TO CHEMIORADIATION FOLLOWED BY SURGERY: A PROPENSITY SCORE ANALYSIS OF RESPONSE AND SURVIVAL ACCORDING TO HISTOTYPE}

${ }^{1} \mathrm{~F}$ Legge ${ }^{*},{ }^{1} \mathrm{~F}$ Murgia, ${ }^{2} \mathrm{~V}$ Gallotta, ${ }^{2} \mathrm{~F}$ Fanfani, ${ }^{3} \mathrm{~A}$ Ercoli, ${ }^{4} \mathrm{~F}$ Cosentino, ${ }^{1} \mathrm{~V}$ Carone, ${ }^{5} \mathrm{LC}$ Turco, ${ }^{6} \mathrm{~V}$ Chiantera, ${ }^{7} \mathrm{~L}$ Pedone Anchora, ${ }^{2} \mathrm{~N}$ Bizzarri, ${ }^{8} \mathrm{G}$ Macchia, ${ }^{9} \mathrm{~V}$ Valentini, ${ }^{2,10} \mathrm{G}$ Scambia, ${ }^{7} \mathrm{G}$ Ferrandina. ${ }^{1}$ F. Miulli' General Regional Hospital, Gynecologic Oncology Unit, Acquaviva Delle Fonti, Italy; ${ }^{2}$ Università Cattolica del Sacro Cuore, Department of Woman and Child Health and Public Health, Woman Health Area, Fondazione Policlinico Universitario A. Gemelli Irccs, Roma, Italy; ${ }^{3}$ Università degli Studi di Messina, Policlinico G. Martino, Division of Gynecologic Oncology, Messina, Italy; ${ }^{4}$ Gemelli-Molise, Università Cattolica del Sacro Cuore, Division of Gynecologic Oncology, Campobasso, Italy; ${ }^{5}$ Mater Olbia Hospital, Gynaecology and Breast Unit, Olbia, Italy; ${ }^{6}$ University of Palermo, Department of Gynecologic Oncology, Arnas Civico Di Cristina Benfratelli, Palermo, Italy; ${ }^{7}$ Fondazione Policlinico Universitario A. Gemelli, IRCCS, Department of Woman and Child Health and Public Health, Rome, Italy: ${ }^{8}$ Gemelli-Molise, Università Cattolica del Sacro Cuore, Radiation Oncology Unit, Campobasso, Italy; ${ }^{9}$ Fondazione Policlinico Universitario A. Gemelli IRCCS, Radiation Oncology Unit, Rome, Italy; ${ }^{10}$ Fondazione Policlinico Universitario A. Gemelli IRCCS and Scientific Directorate, Gynecologic Oncology Unit, Rome, Italy

\subsection{6/ijgc-2021-IGCS.151}

Objectives The frequency of adenocarcinoma (AC) of the uterine cervix, although considered a rare entity, increased over the last 4 decades and, nothwithstanding previous studies reported a worse outcome compared to squamous cell carcinoma (SCC), standard treatment remains identical. Insight in the impact of histological types on biological behavior and pathological complete response rates might result in a treatment paradigm shift.

Methods Beginning with 548 locally advanced cervical cancer (LACC) patients submitted to chemoradiation (CTRT) plus radical surgery (RS), propensity score matching resulted in 320 cases (240 in the SCC and 80 in the AC group), balanced for age, grade, stage and lymph node status.

Results AC and SCC groups did not differ in terms of baseline characteristics as well as rates of surgical camplications. Pathological response rates to CTRT were significantly lower in the ADC vs SCC arm with complete response rates of $20 \%$ vs $36.2 \%(p=0.001)$. AC showed worse survival outcomes with median disease-free survival (DFS) of 119.5 vs 151.6 months $(\mathrm{p}=0.019)$ and median overall survival (OS) of 134.5 vs 162.9 months $(\mathrm{p}=0.048)$ in AC vs SCC, respectively. In the multivariate analysis, AC histotype $(R R=1.939 ; p=0.005)$, nodal status at imaging $(R R=1.769$; $\mathrm{p}<0.001)$, and stage III or greater $(R R=2.172 ; \mathrm{p}=0.003)$ were associated with worse DFS, whereas only stage and nodal status at imaging were independent risk factor for poorer OS.

Conclusions The lower response rate to chemoradiation and the higher independent risk of recurrence showed by AC with respect to SCC patients could be useful to tailor different therapeutic strategies for LACC according to histotype.

\section{EPV084/\#549 ROLE OF DOSE-DENSE NEOADJUVANT CHEMOTHERAPY WITH PACLITAXEL AND CARBOPLATIN IN LOCALLY ADVANCED CERVICAL CANCER}

${ }^{1} \mathrm{~F}$ Multinu*, ${ }^{2} \mathrm{M}$ Lapresa, ${ }^{2} \mathrm{~V}$ Minicucci, ${ }^{3} \mathrm{~S}$ Gandini, ${ }^{2} \mathrm{G}$ Parma, ${ }^{4} \mathrm{~F}$ Peccatori, ${ }^{2} \mathrm{~F}$ Tomao, ${ }^{1}$ I Betella, ${ }^{1} \mathrm{~A}$ Garbi, ${ }^{1} \mathrm{G}$ Schivardi, ${ }^{1} \mathrm{G}$ Aletti, ${ }^{1} \mathrm{~V}$ Zanagnolo, ${ }^{1} \mathrm{~A}$ Maggioni, ${ }^{5} \mathrm{~N}$ Colombo. ${ }^{1}$ IEO, European Institute of Oncology IRCSS, Division of Gynecologic Surgery, Milan, Italy; ${ }^{2}$ IEO, European Institute of Oncology IRCCS, Gynecologic Oncology, Milan, Italy; ${ }^{3}$ IEO, European Institute of Oncology IRCCS, Department of Experimental Oncology, Milan, Italy; ${ }^{4}$ IEO, European Institute of Oncology IRCCS, Fertility and Procreation Unit, Division of Gynecologic Oncology, Milan, Italy; ${ }^{5}$ University of Milan-Bicocca, European Institute of Oncology, IRCCS, Gynecologic Oncology Program, Milan, Italy

\subsection{6/ijgc-2021-IGCS.152}

Objectives To evaluate the role of dose-dense neoadjuvant chemotherapy(NACT) with paclitaxel and carboplatin before surgery in locally advanced cervical cancer(LACC).

Methods Patients with LAAC (Stage Ib2-IVa) undergoing dosedense NACT at the European Institute of Oncology, Milan from July 2014 to February 2019 were identified. Patients received weekly dose-dense carboplatin (AUC2 or AUC2.7) and paclitaxel ( 80 or $60 \mathrm{mg}$ ) for 6-9 cycles followed by surgery. Radiological response was evaluated by RECIST. Pathologic response was evaluated based on the final pathology report.

Abstract EPV084/\#549 Table 1 Baseline characteristics of the overall population $(n=68)$

\begin{tabular}{|c|c|c|c|}
\hline & Median (range) & & \\
\hline Age, years & $43(26-67)$ & & \\
\hline Tumor diameter, $\mathrm{mm}$ & $15(0-70)$ & & \\
\hline \multirow[t]{2}{*}{ Time to chemotherapy, days } & $41(6-405)$ & & \\
\hline & & n. & $\%$ \\
\hline \multirow[t]{4}{*}{ Histotype } & Squamous & 51 & 75.00 \\
\hline & Adenocarcinoma & 14 & 20.59 \\
\hline & Adeno-Squamous & 2 & 2.94 \\
\hline & Other & 1 & 1.47 \\
\hline \multirow[t]{4}{*}{ Tumor Grade } & G1 & 6 & 11.32 \\
\hline & G2 & 23 & 43.40 \\
\hline & G3 & 24 & 45.28 \\
\hline & Unknown & 15 & \\
\hline \multirow[t]{3}{*}{ LVSI on biopsy } & Yes & 4 & 7.02 \\
\hline & No & 53 & 92.98 \\
\hline & Unknown & 11 & \\
\hline \multirow{3}{*}{ Performance Statuss. } & 0 & 66 & 98.51 \\
\hline & 2 & 1 & 1.49 \\
\hline & Unknown & 1 & \\
\hline \multirow[t]{2}{*}{ Site of chemotherapy } & IEO & 45 & 66.18 \\
\hline & Non-IEO & 23 & 33.82 \\
\hline \multirow[t]{6}{*}{ Number cycle dose-dense } & 5 & 7 & 10.45 \\
\hline & 6 & 41 & 61.19 \\
\hline & 7 & 3 & 4.48 \\
\hline & 8 & 4 & 5.97 \\
\hline & 9 & 12 & 17.91 \\
\hline & Unknown & 1 & \\
\hline \multirow[t]{3}{*}{ Dose Carboplatin (AUC) } & 2 & 51 & 83.61 \\
\hline & 2.7 & 10 & 16.39 \\
\hline & Unknown & 7 & \\
\hline \multirow[t]{3}{*}{ Dose Paclitaxel, mg/ma } & 80 & 11 & 18.03 \\
\hline & 60 & 50 & 81.97 \\
\hline & Unknown & 7 & \\
\hline \multirow[t]{6}{*}{ Stage FIGO 2018 at diagnosis } & IB2 & 18 & 26.47 \\
\hline & IB3 & 28 & 41.18 \\
\hline & IIA1 & 3 & 4.41 \\
\hline & IIA2 & 3 & 4.41 \\
\hline & IIB & 6 & 8.82 \\
\hline & IIIC1 & 10 & 14.71 \\
\hline \multirow[t]{3}{*}{ Disruption of stromal ring } & Yes & 31 & 48.44 \\
\hline & No & 33 & 51.56 \\
\hline & Unknown & 4 & \\
\hline
\end{tabular}

Abbreviations: LVSI: Lymphovascular space invasion; IEO: European Institute Oncology 